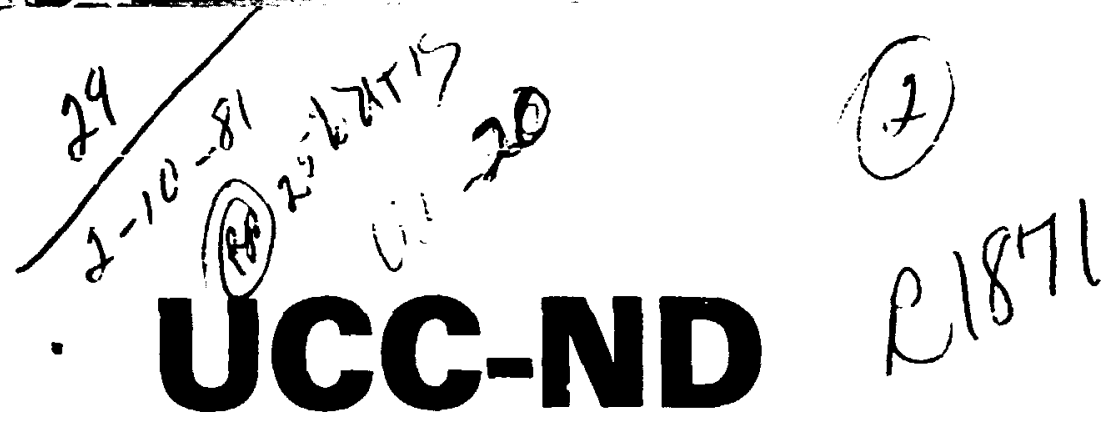

NUCLEAR DIVISION

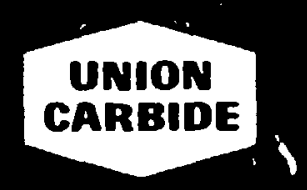

\title{
Recalling ISX Shot Data Files from the Off-Line Archive
}

J.S. Stanton

OPERATED BY

UNION CARBIDE CORPOBBTION FOR THE UNITED STATES DEPARTMENT OF ENERG 
ORNL/CSD/TTi-138

\title{
RECALLING ISX SHOT DATA FILES FROM THE OFF-LINE ARCHIVE
}

J. S. Stanton

\author{
Sponsor: C. E. Hammons
}

Date Published - February 1981

COMPUTER SCIENCES DIVISION

at

Oak ridge National Laboratory

Post Office Box $X$

Oak Ridge, Tennessee 37330
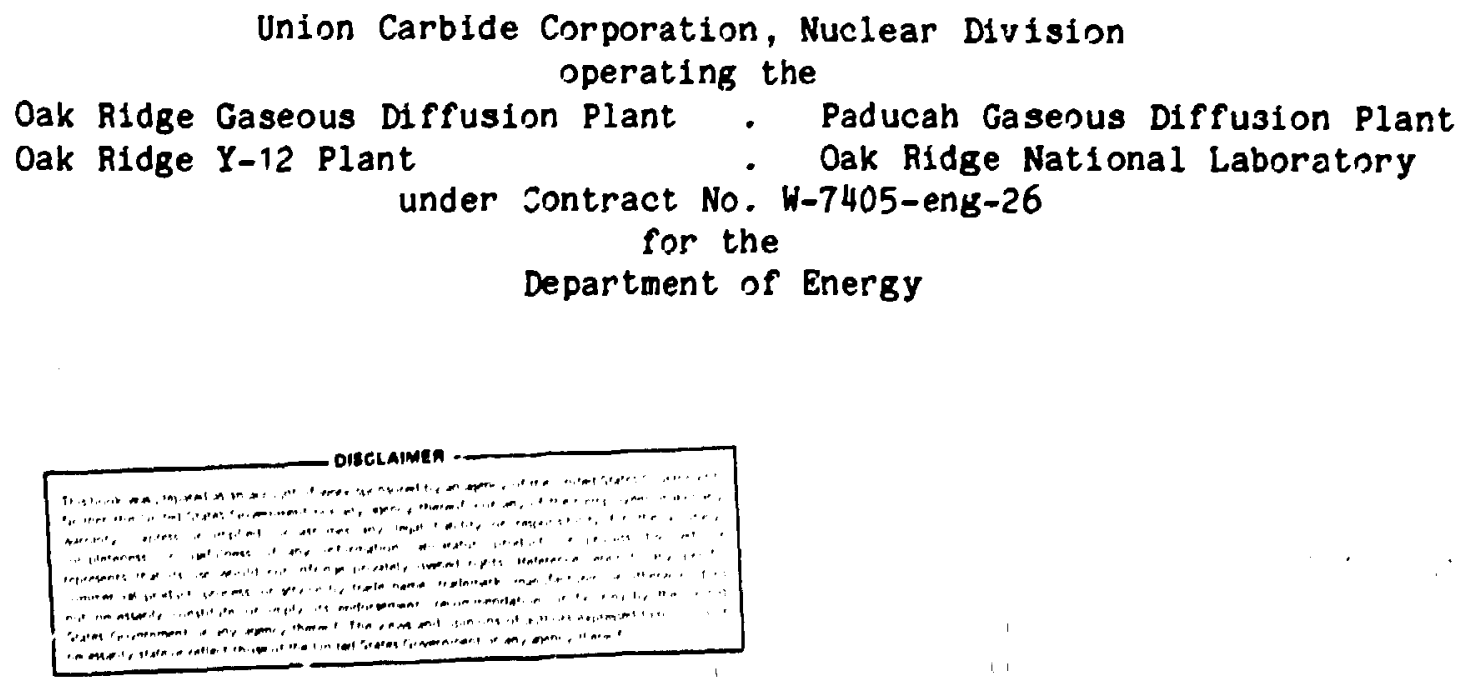
TABLE OF CONTENTS

ACRNOHLDGMEHTS . . . . . . . . . . . . . . . . . v v

ABSTRACT .......................... 1

i. USER'S GUIDE ......................... 3

1.1 INTRODCCTION .................... 3

1.2 THE QUEUE RECALL REQUEST PROGRAM .............. 3

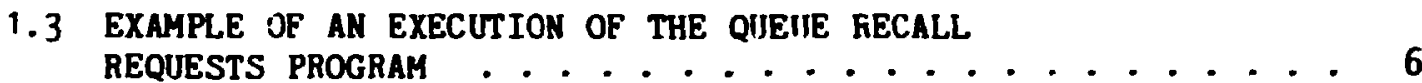

1.4 LISTING OF THE FILE TEST. DAT USED IN THE QRCL EXAMPLE . . - 8

1.5 BATCH EXECUTION FOR THE QUEUE RECALL REQUESTS PROGRAM - . . 8



1.6 .1 ".DO LSTGRP Request-id" ........... 11

1.6 .2 ".DO LSTGCT Partial-request-id" ........... 11

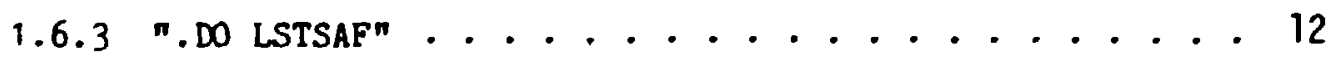

1.6 .4 n.DOLSTSHT ................. . . . 13

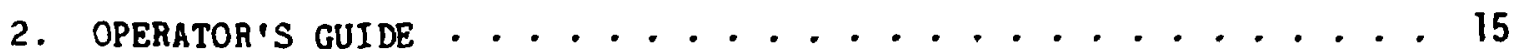

2.1 INTRODUCTION ......................... 15

2.2 INTERROGATION OF THE RECALL REQUEST QUEUE . . . . . . . 15

2.2 .1 "DO PAKLST" ................. 16

2.2 .2 "DO PAKAGE" .................. 16

2.2 .3 "DO AGE" ...................... 17

2.3 SATISFYING REQUESTS FOR PACK MOUNTS . . . . . . . . . 17

2.3.1 "DO INEPAK XXX" .................... 18

2.3 .2 "DO ALLPAK" . . . . . . . . . . . . . 19 


\section{ACKNOHLEDGMENTS}

This document was generated as a result of a project sponsored by the Crouter Support Group of the Fision Energy Division. 


\section{ABSTRACT}

This document describes a set of compute* programs designed to allow access to ISX shot data files stored on off-line disk packs. The programs accept user requests for data files and build a queue of end requests. When an operator is available to mount the necessary disk packs, the system copies the requested files to an on-line disk area. The programs run on the Fusion Errergy Division's DECsystem-10 computer. The request queue is impiemented under the System 1022 (TM) data base management system. The support programs are soded in MACRO-10 and FORTRAN-10. 


\section{USER'S GUIDE}

\subsection{INTRODUCTION}

ISX shot data files are archived on a series of mountable disk packs. Since only a limited number of packs may be on-Iine at any one time, a data file trat is required may not be available. In order to reduce the inconvenience caused by the off-line data files, a system to copy files from the archive packs to an on-line area has been developed. The system is called the ISX recall system (RECALL).

The RECALL system accepts as input lists of shot numbers to be copie into the on-line area. The lists are placed in a queue of recall requests. The queue may be scanned to determine the status of one or all requests. When an operator is available to mount the off-line disk packs, a batch job is created which issues MOUNT commands for the necessary packs and copies the requerted files.

\subsection{THE QUEUE RECALL RFQUEST PROGRAM}

The queue recall request program (QRCL) places shot numbers in the recall queue. The recall queue is actually a systen 1022 data base (System 1022 is a generai purpose data base management system). QRCL makes one entry in the queue for each shot file requested. The queue may then be interrogated using the interactive seatures of System 1022. QRCL requires as input a list of the shot numbers to be recalled. The list may be entered from a terminal or it may be in a flie. In either case, the shot numbers are entered one to a line with an optional file letter precsding the number. The file letter is used to differentiate between the many data sets generated during each shot. 

A response of "Y" instructs QRCL to list a brief set of instructions on the user's terminal. Any other entry instructs QRCL to skip the instructions.

"DO YOU WANT TO SEE ARCHIVE INFORMATION MESSAGES? (Y/N):"

Entering "Y" or (return) causes QRCL to list information concerning the archive losation of each shot in the recall request. An entry of "N" suppresses this listing.

"ENTER AN ID FOR THIS GROUP OF SHOTS:"

The user must enter at least one character and no more than ten to identify this recall request. The value entered may be used to check the status of the request.

"ARE SHOT NUMBERS IN A FILE? ( $Y / N):$ "

A response of "Y" or (return) directs QRCL to ask for the name of the file that contains the shot numbers. The form of that question is:

"Enter new flle specs. End with an $\$(A L T) "$

respond with the name of the file.

A response of "N" to the "in a flle" question causes QRCL to prompt for a list of shot numbers from the terminal. The form of that prompt is: 
"ENTER THE FILE LETTER AND SHOT "

respord with the shot numbers needed, one to a line. End with a blank line, i.e., two carriage returns.

"ANY MORE SHOTS? (N/Y):"

After a list of shot numbers has been pirocess $₫ d$, ORCL asks this question. If more shot numbers are tc be entered in the queve, respond with "Y"; otrerwise enter "N" or (return).

1.3 EXAMPLE OF AN EXECUTION OF THE QUEUE RECALL REQUESTS PROGRAM

.RUN QRCL[230,2301]

WOULD YOU LIKE TO SEE THE HELP FILE? (N/Y):Y

QRCL IS THE PROGRAM USED TO QUEUE REQUESTS FOR RECALL OF ARCHIVED ISX DATA FILES. THE REQUESTS ARE ACCUMULATED UNTIL AN OPERATOR IS AVAILABLE TO MOUNT THE NEEDED ARCHIVE DISK PACKS.

QRCL EXPECTS A LIST OF SHOT NUMBERS OPTIONALLY PRECEDED BY A FILE LETTER. THE LIST MAY BE ENTERED FROM THE USER'S TERMINAL OR A FILE.

THE FIRST QUESTION ASKED BY QRCL AFTER THE HELP PROMPT CONCERNS THE PRINTING OF THE ARCHIVE LOCATION OF EACH OF THE REQUESTED SHOTS. THIS INCLUDES THE DISK PACK AND SUBFILE DIRECTORY (SFD) THE SHOT IS ARCHIVED UNDER.

THE NEXI PROMPT REQUESTS THAT THE USER ENTER A NAME POR THIS GROUP OF SHOTS. THIS NAME IS USED TO CHECK THE STATUS OF A RECALL $P$ - ZUEST. THE RECOMMENDED FORMAT CONSISTS OF THE USER'S INITIMLS FOLLOWED BY 1 TO 7 LETTERS OF UNIQUE IDENTIFICATION.

THE NEXT QUESTION ASKS IF THE SHOT LIST IS IN A FILE OR IF IT WILL BE ENTERED FROM THE USER'S TERMINAL.

IF THE FILE OPTION IS SELECTED, QRCL WILL ASK FOR THE NAME OF THE FILE. THE FILE SHOIJLD BE IN ASCT? WITH ONE SHOT PER LINE LEFT JUSTIFIED. IF A PILE LETTER IS SPECIFIED, IT MUST BE THE FIRST CHARACTER ON THE LINE.

FOR THE TERMINAL OPTION THE PROGRAM WILL PROMPT THE USER TO ENTER PILE LETTERS AND SHOT NUMBERS. THE FILE LETTER IS OPTIONAL. TO EXIT FROM THE INPUT SEQUENCE, ENTER A BLANK LINE OR A (CNTRL)Z. 
FIMALLY QRCL ASRS IF THE USER WANTS TO ENIER RNY MORE SHOTS. A RESPONSE OF YFS CAUSES THE PROGRAM TO RETURN TO THE "AKE SHOT NUMBERS IN A FILE PROHPT". DO YOU WANT TO SE: ARCHIVE MESSAGES (Y/N):Y

ENTER AN ID FOR THIS GROUP OF SHOTS:TST11D

ARE SHOT NUMBERS IN A FILE?(Y/M):I

Unit=2 DSK: RECALL. DAT/ACCESS=SEQIN/MODE=ASCII

Enter new file specs. End with an $\$(A L T)$

-TEST.DAT\$

\begin{tabular}{|c|c|c|c|c|c|c|}
\hline \multirow{2}{*}{$\begin{array}{l}\text { FL } \\
\text { B }\end{array}$} & SHOT & SF D & PACK & FLAGS & LSFD & HSI \\
\hline & 9456 & 0447 & 003 & 0 & 03 & $04^{\circ}$ \\
\hline & 17310 & 1034 & 005 & 0 & 1001 & \\
\hline \multirow[t]{3}{*}{ C } & 17798 & 1054 & 00 & 0 & 100 & \\
\hline & 17798 & 10 & 00 & 0 & 100 & \\
\hline & 123 & 0 & 00 & & & \\
\hline A & 10234 & 0 & 00 & & & \\
\hline$G$ & 4345 & 02 & 00 & & & \\
\hline 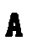 & 9456 & 0447 & 003 & 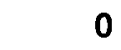 & 03 & \\
\hline \multicolumn{2}{|c|}{ SHOT : 81567} & \multicolumn{5}{|c|}{ HAS NOT BEEN ARCHIVED. } \\
\hline $\mathbf{s}$ & 678 & 0025 & 001 & 0 & 000 & 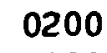 \\
\hline \multirow[t]{2}{*}{$\mathbf{S}$} & 123 & 0003 & 001 & 0 & 00 & 2 \\
\hline & 1023 & 0477 & 003 & 0 & 0366 & $4^{\prime}$ \\
\hline & 431 & 0207 & 002 & 0 & 0201 & \\
\hline & 9456 & 0447 & 003 & 0 & 0366 & 4 \\
\hline & $:: 8$ & YA & EE & ARCHI & & \\
\hline
\end{tabular}

16: IMPUT 14 :QUEUED 2. NOT POUND

ANY MORE SHOTS? (N/Y): Y

ARE SHOT NUMBERS IN A FILE?(Y/N):N

ENTER PILE LETTER AND SHOT N2345

FL SHOT SFD EACK FLAGS LSFD HSFD



ENTER FILE LETTER AND SHOT \#123!15

FL SHOT SFD PACK PLAGS LSFD HSFD

$\begin{array}{llllll}12345 & 0601 & 004 & 0 & 0500 & 1000\end{array}$

ENTER FILE LETTER AMD SHOT WXYZ

ERROR ON INPUT OF SHOT NUMBER. XYZ

ENTER FILE LETTER AND SHOT 9999

FL SHOT SFD PACK PLACS LSFD HSFD $\begin{array}{llllll}3999 & 0470 & 003 & 0 & 0366 & 4477\end{array}$

ENTER FILE LETTER AND SHOT

20:INPUT 17: CUEUED 3:NOT FOUND

ANY MORE SHOTS? (N/Y):N 
STOP

END OF EXECUTION

CPL TIME: 1.52 ELAPSED TME: 16.60

EXIT

1.4 LIST LNG OF THE FILE TEST. DAT USED IN THE ORCL EXAMPLE
B9456
17310
C17798
L 17798
123
A 10234
G4345
A9456
81567
5678
$\$ 123$
10234
P4345
A9456
K81567
P678

1.5 BATCH EXECUTION FOR THE QUEUE RECALL REQUESTS PROGRAM

A commarid file has been created which allows a user to run the QRCL program in a batch mode. To use this feature, make a file of shots to be recalled and then enter:

.DO BATQUE[ 230,2301$]$ request-1d,file-spec

EXAMPLE

.DO BATQUE[230,2301] TST44,TEST.DAT

- DEL BQ.CTL

Files deleted:

BQ.CTL

01 Blocks freed

.MAKE BQ.CTL

- I.RUN QRCL

N

Y

TST 44 
$r$

TEST.MT:

sents

.SUBart BQ.CTL

Sapple los flile produced by Butore

$10: 47: 09$ 8A.0B 10:47:09 9AFT:

$10: 47: 09$ BAFIL

10:47:09 8A504

BAtcol version 13(1071) cunning Ba sequence 5923 in strean I for $\mathrm{XZ}$ Input Tron DSWO:BQ.CTL[ $200, \mathrm{mr}]$

Output to DSLDO:BQ.LOG $[\mathrm{xxx}, \mathrm{m})]$

Job paracters

IIne:00:05:00 Unique:TES Restart-100

$10: 47: 13$ motr

$10: 47: 13$ monta

$10: 47: 13$ USER

$10: 47: 14$ USER

$10: 47: 16$ moirta

$10: 47: 16$ MOT:T

$10: 47: 17$ sown

10:47:17 Momt:

10:47:17 USER

10:47:19 USEA

$10: 47: 19$ USER

$10: 47: 19$ USER

$10: 47: 19$ USER

$10: 47: 19$ USEE

10:47:19 USER

$10: 47: 19$ USER

$10: 47: 15$ USER

$10: 47: 19$ USER

$10: 47: 19$ USEA

$10: 47: 19$ USER

$10: 47: 19$ USEA

$10: 47: 19$ USER

$10: 47: 19$ USEK

$10: 47: 19$ USER

$10: 47: 10$ USER

$10: \$ 7: 19$ USER

$10: 47: 20$ USER

$10: 47: 20$ USER

$10: 47: 21$ USER

$10: 47: 22$ USER

$10: 47: 23$ USER

$10: 47: 24$ USER

$10: 47: 24$ USER

$10: 47: 25$ USEA

$10: 47: 25$ USER

$10: 47: 26$ USER

$10: 47: 26$ USER

$10: 47: 27$ USER

$10: 47: 27$ USER

$10: 47: 28$ USER

$10: 47: 28$ USER

LOcta $x \mathrm{xa} / \mathrm{s}$

JOB 40 ORAL Fusion Energy 6032 TTY162

:027 17-Apr-80 Thur

.LOCATE

DODE FEDusC(1) OAML Fustion Enersy 603a 09-05-i9 Lxeatod

.. BOI QRCL

WOUD TOU LIXE TO SEE THE HELP FILE? ( $\mathrm{B} / \mathrm{Y}$. *

DO IOU WAIT TO SEE MACHIVE MESSACES ( $\mathrm{I} / \mathrm{H}):$ :

ETER AII ID FOR THIS GROUP OF SHOTS:TST W

ARE SHOT MURBERS IH \& RILE?(T/M):I

UnIt=2 DSR: RECALL. CAT/ACCESS =SEOIN/HODE=ASCII

Enter new file specs. End wtth an s(ALI)

-test.dats

FL SHOT SFD PACK PLAGS LSFO HSFD

$\begin{array}{llllll}\text { 8 } 3456 & 0447 & 003 & 0 & 0366 & 0477\end{array}$

$\begin{array}{llllll}17310 & 1034 & 005 & 0 & 1001 & 1125\end{array}$

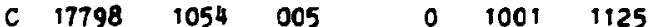

l $\quad \begin{array}{llllll}17798 & 054 & 005 & 0 & 1001 & 1125\end{array}$

$\begin{array}{llllll}123 & 0003 & 001 & 0 & 0001 & 0200\end{array}$

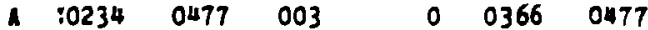

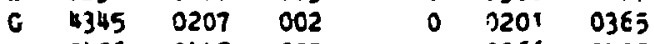

$\begin{array}{lllllll}1 & 9456 & 0447 & 003 & 0 & 0366 & 0477\end{array}$

SHOT:81567 HAS NOT BEEN ARCHIVED.

S $\quad 6780025001 \quad 000010200$

$\begin{array}{lllllll}5 & 123 & 0003 & 001 & 0 & 0001 & 0200\end{array}$

$\begin{array}{llllll}10234 & 0477 & 003 & 0 & 0366 & 0477\end{array}$

$\begin{array}{llllll}13450207 & 002 & 0 & 0201 & 0365\end{array}$

$\begin{array}{lllllll}1 & 9456 & 0447 & 003 & 0 & 0366 & 0477\end{array}$

SHOT:8:567 HAS WOT BEEN ARCHIVED.

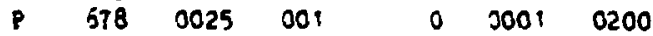


$10: 47: 28$ USER

$10: 47: 28$ USER

$10: \div 7: 28$ USER

$10: 47: 28$ USER

$10: 47: 28$ USER

$10: 47: 28$ USER

$10: 47: 26$ MONTR

$10: 47: 28$ MONTR

$10: 47: 28$ MONTR

$10: 47: 29$ LGOUT

$10: 47: 29$ LGOUT

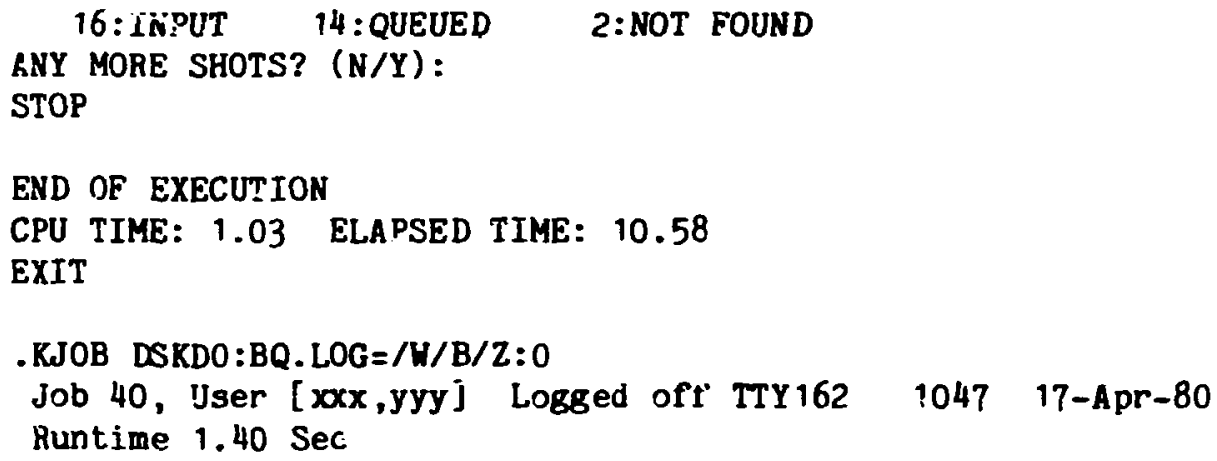

1.6 USER COMANDS FOR INTERROGATION OF THE RECALL REQUEST QUEUE A number of MIC commands nave been developed to allow a user of the RECALL system to inquire about the status of a recall request. To accesi commands, PPN [ZZ30,2301] should be estab]ished as a library. This may be accomplished by entering the following commands.

\section{- R SETSRC \\ LIB[230.2301] \\ (CNTRL)C}

Anotiser way to establish a library is to place a file called SWITCH.INI in one's on-line disk area. The file may be created with a.l Editon such as TECO. The sontent of the file shouid be the following:

LOGIN/LIB: $[230,2301]$

The SWITCH.INI file nas a number of other uses which are documented in the Uperating System Command Manua 1. 


\subsection{1 ".DO LSTGRP request-id"}

Produces a listing of those shots which have yet to be recalled to the on-line area from the recall request list named "request-id".

\section{EXAMPLE}

DO LSTGRP TST 11D

.R 1022

$4 / 17 / 80$

System 1022 A (114B)

- eCR

RECALL FILE OPEN.

73 RECS FOUND.

- FIND BATCH EQ "TST11D"

17 RECS FOUND.

- etr

BATCH

TST 11D

TST:1D

DATE REQ. APR-17-1980 APR-17-1980

TST11D APR-17-1980

\section{SHOT}

123

123

SFD PACK

$0003 \quad 001$

$0003 \quad 001$

$0025 \quad 001$$$
\text { - }
$$

TST 11D

TST 11D

TST 11D

- 0

EXIT
APR-01-198x

\section{5 .2 ".DO LSTGCT partial-request-idn}

Generates a list of all shots which are in the queue and belong to a group of shots that have the string "partial-request-1d" in their request identifier.

EXAMPLE

.DO LSTGCT TST

.f 1022

$4 / 17 / 80$

System 1022A (114B)

- eOR

RECALL FILE OPEN.

73 RECS FOUND. 
- FIND BATCH CT nTST" 26 RECS FOUND.

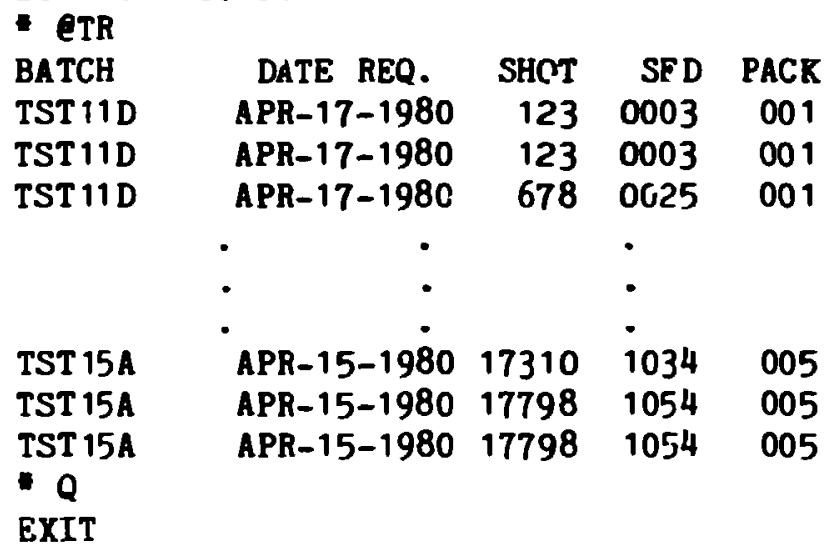

\section{6 .3 ".DO LSTSAF"}

Lists all of the shot data files in the queue, with a count of the number of requests for each file.

EXAMPLE

.DO LSTSAF

.R 102.2

$4 / 17 / 80$

System 1022A (114B)

- elstsaf

RECALL FILE OPEN.

73 RECS FOUND.

00123: 4

S00 123: 4

TOTAL REQUESTS FOR SHOT $00123=8$

PUÓ́78: 4

S00678: $\quad 4$

TOTAL REQUESTS FOR SHOT $00678=8$

A00987 :

1

TOTAL REQUESTS FOR SHOT $00987=1$

E02345: 1

N02345: 2

P02345: 1

Q02345: 1

TOTAL REQUESTS FOR SHOT $02345=5$

32500: 1

TOTAL REQUESTS FOR SHOT $32500=1$ 32700: 1

TOTAL REQUESTS FOR SHOT $32700=1$ 


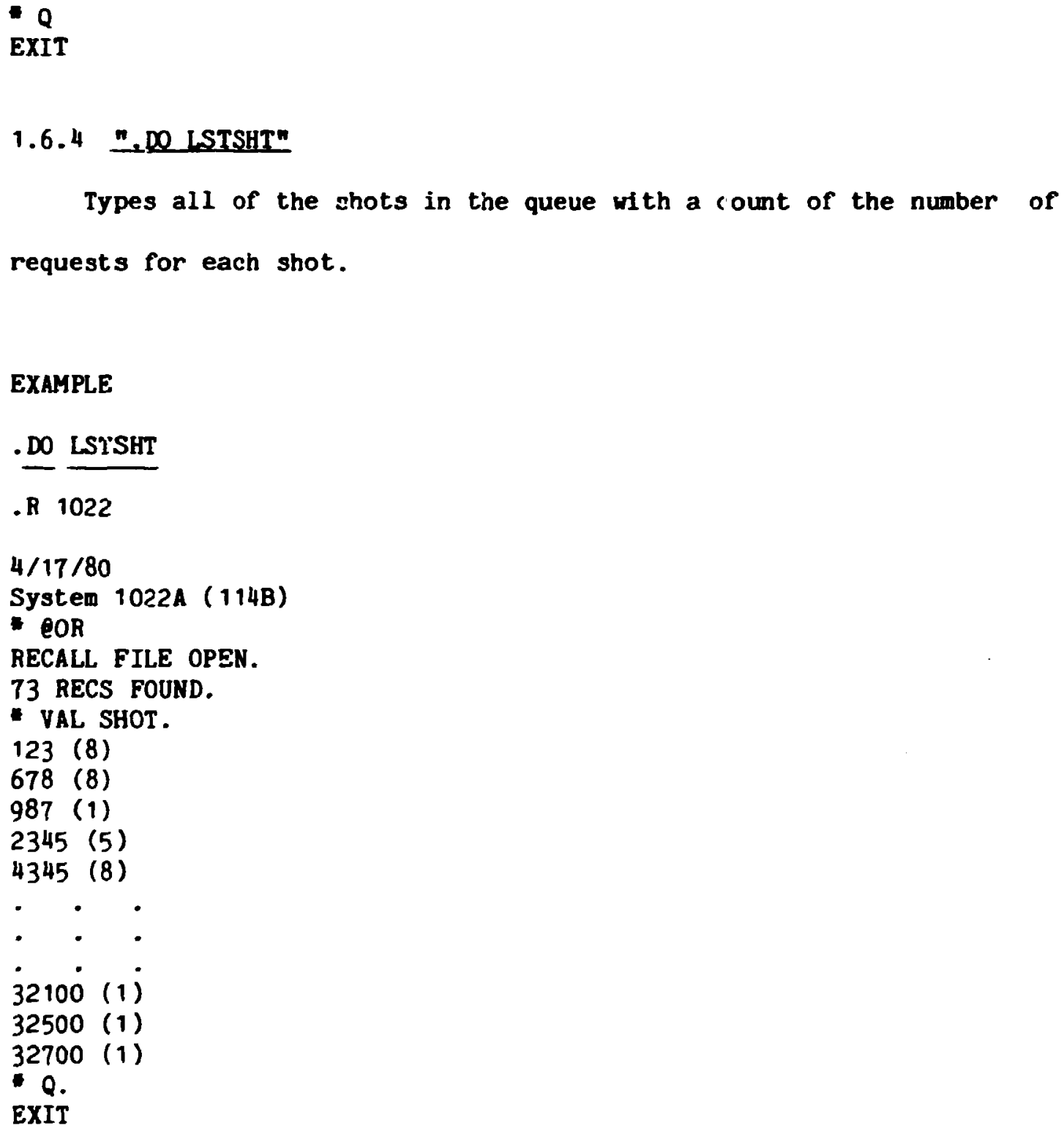




\section{OPERATOR'S GUIDE}

\subsection{INTA' ITION}

The function of the operator in the ISX RECALL system is to mount the archive disk packs needed to satisfy users' requests for shot data files. The recall requests are stored in a System 1022 (TM) data base. The data base may be queried using a set of MIC commands developed for the sperator or with stanoard System 1022 commands. The main items of interest to the sperator are the number of packs to be mounted and how long the requests for those packs have been pending. Three MIC commands are available to answer questions about the above items: PAKLST; lists the identification of each pack to be mounted and the number of requests for each pack. PAKAGE; outputs the age of the requests for each pack, and AGE; lists the requests by date of entry. After the RECALL queue has been examined, the next action by the operator is to satisfy one or more of the pack mount requests. Two MIC ommands have been implemented for this function: ONEPAK which creates a batch job to mount a single specifiej pack and copy the requested files from it to the on-line ISX pack; and ALLPAK which generates a batch job to mount and copy files from all requested packs.

\subsection{INTERROGATION OF THE RECALL REQUEST QUEJE \\ The following MIC commands are for use by the operator of the RECALL system to determine number and nature of pack requests in the recall queve.}




\subsection{3 "DO PARLST"}

Ienerate: a list of the packs to be mounted with a count of the number of requests for each pack.

EXAMPLE

DO PARLST

. 1022

$6 / 17 / 80$

System 1022A (114B)

- eOR

RECALL FILE OPEN.

16 RECS FOUND.

- ePL

TOKOOO REQUESTS: 5

TOKO0 1 REQUESTS: 8

TOK002 REQUESTS: 3

TOTAL OF 3 PACKS TO MOUNT.

- $Q$

EXIT

\subsection{2 "DO PAKAGE}

Creates " listing of the age of the requests for each pack in the recall request queue.

EXAMPLE

.DO FAKAGE

.R 1022

$6 / 17 / 80$

System 1022A (114B)

- eOR

RECALL FII.E OPEN.

16 RECS FOUND.

- ePAKAGE

16 RECS FIIUND.

PACK TOKONO

1 REQUESTS 127 DAYS OLD.

2 REQUESTS 31 DAYS OLD.

1 REQUESTS 16 DAYS OLD.

PACK TOK001

1 REQUESTS 7 DAYS OLD.

2 REQUESTS 94 DAYS OLD.

1 REQUESTS 73 DAYS OLD. 


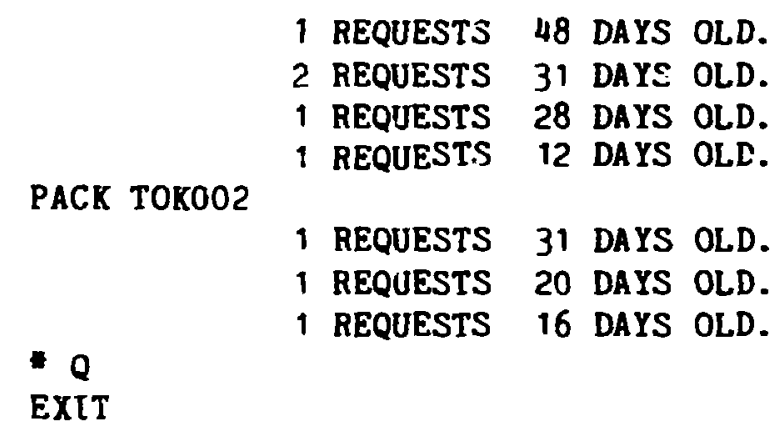

\section{2 .3 "DO AGE"}

Outputs the recall requests from the oldest to the most recent.

EXAMPLE

.DO AGE

.R 1022

$6 / 17 / 80$

System 1022A (114B)

- eOR

RECALL FILE OPEN.

16 RECS FOUND.

- eAGE

16 RECS FCUND.

PACK TOKOOO HAS

PACK TOKOO 1 HAS

PACK TOKOO 1 HAS

PACK TOKOO 1 HAS

PACK TOKOOO YAS

1 REQUESTS 127 DAYS OLD.

2 REQUESTS 94 DAYS OLD.

1 REQUESTS 73 DAYS OLD.

1 REQUESTS 48 DAYS OLD.

PACK TOKOO 1 HAS

2 REQUESTS 31 DAYS OLD.

PACK TOKO02 HAS

2 REQUESTS 31 DAYS OLD.

PACK TOKOO 1 HAS

1 REQUESTS 31 DAYS OLD.

FACK. TOKO02 HAS

1 REQUESTS 28 DAYS OLD.

PACK TOKOOO HAS

1 REQUESTS 20 DAYS OLD.

PACK TOKO02 HAS 1 REQUESTS 16 DAYS OLD.

PACK TOKOO 1 HAS 1 REQUESTS 12 DAYS OLD.

PACK TOKOOO HAS 1 REQUESTS ? DAYS OLD.

- $Q$

EXIT

\subsection{SATISFYING REQUESTS FOR PACK MOUNTS}

The following MIC commands are used to bulld tatch control files

that will request the mounting of archive disk packs and then copy the 
desired files to the on-line ISX pacx. After a control file has been created, enter: "SUBMIT RECALL" to start the batch job.

\section{3.? "IDO ONEPAK XXX"}

Develops a batch job which will mount pack "xxx" and copy the requested sho: data files to the on-line pack.

\section{EXAMPLE}

.DO ONEPAR 001

.$R 1022$

$6 / 17 / 80$

System 1022A (114B)

- eOR.

RECAL: FILE OPEN.

11 KECS FOUND.

- UPDATE ON.

- FIND PACK EQ 001.

O RECS FOUND.

- eGU.

6 RECS FOUND.

- SORT SFD SHOT FLET.

- init 1 recall. dat.

- LET SySREPMODE 0.

- pRint on 1 PACK SFd FLET SHOT FMT A3 A4 A1 P99999 END.

- release 1.

- dump data pO01.hld desC Recall. Dmd.

- deLETE.

- UPDATE OFF.

- Q.

EXIT

. RUN MAKJOB

PACK TOKOO 1 REQUESTS: 6

STOP

END OF EXECUTION

CPU TIME : 0.08

EXIT

ELAPSED TIME: 1.03

.SUBMIT RECALL 


\section{3 .2 "DO ALLPAR"}

Generates a batct. control file that mounts $a^{-}$. of the packs in the recall request queue.

EXAMPLE

.DO ALLPAK

.R 1022

$6 / 17 / 80$

System 1022A (1148)

- eor

RECALL FILE OPEN.

16 RECS FOUND.

- eR2

14 RECS FOUND.

16 RECS FOUND.

System 1022 Data Loading Program

No errors on DESCRIPTION file

no input data found; 0 records loaded

EXIT

.RUN MAKJOB

PACK TOKOOO REQUESTS: 5

PACK TOKO01 REQUESTS: 6

PACK TOKO02 REQUESTS: 3

STOP

END OF EXECUTION

CPU TIME: 0.14

ELAPSED TIME: 1.43

EXIT

.SUBMIT PECALL 